\title{
A LATITUDINAL GRADIENT IN RECRUITMENT OF INTERTIDAL INVERTEBRATES IN THE NORTHEAST PACIFIC OCEAN
}

\author{
Sean R. Connolly, ${ }^{1,3}$ Bruce A. Menge, ${ }^{2}$ And Joan Roughgarden ${ }^{1}$ \\ ${ }^{1}$ Department of Biological Sciences, Stanford University, Stanford, California 94305-5020 USA \\ ${ }^{2}$ Department of Zoology, Cordley 3029, Oregon State University, Corvallis, Oregon 97331 USA
}

\begin{abstract}
Rates of propagule supply can be important determinants of spatial and temporal patterns in community structure. In the northeast Pacific Ocean, large-scale differences in the structure of intertidal invertebrate communities have been attributed to a latitudinal gradient in recruitment in this region. To determine whether such a gradient exists, recruitment of intertidal barnacles and mussels was monitored at 17 sites across this region in 1996 and 1997. A latitudinal gradient in recruitment was detected in this study. This gradient was approximately a stepcline: annual recruitment, on average, was 1-2 orders of magnitude higher in central and northern Oregon than in central and northern California. In contrast to the regional differences, large-scale gradients in recruitment within California were small; correlations of recruitment with latitude were weak, and in all but one case, statistically insignificant. Nonetheless, trends in the data suggest that recruitment within central and northern California was highest between San Francisco and Monterey Bay, where larvae may be retained more nearshore than to the north or south. If so, apparently conflicting claims about latitudinal gradients in recruitment within California can be reconciled. The large-scale transition in recruitment rates supports the hypothesis that a marked shift in the intensity of upwelling near Cape Blanco in southern Oregon is a major cause of a coincident transition in community structure. Stronger upwelling (and thus offshore flow) to the south has been hypothesized to transport larvae further offshore and thereby reduce larval supply to nearshore benthic communities.

This study confirms that the predicted differences in recruitment exist, and that these differences are large. Preliminary calculations indicate that regional differences in offshore flow are likely to make a larger contribution to the recruitment transitions than several other plausible causes. In addition, recruitment transitions are larger, more abrupt, and more consistent across species than corresponding shifts in percentage cover, which favor competitive dominants. This supports model predictions that competition for space is more intense where recruitment is high. However, the absence of strong, large-scale recruitment gradients within California suggests that mesoscale processes are relatively more important than latitudinal trends in upwelling as determinants of community structure patterns at smaller scales.
\end{abstract}

Key words: Balanus; barnacles; benthic-oceanic coupling; Chthamalus; intertidal community; larval supply; larval transport; latitudinal gradient in recruitment; mussels; Mytilus; recruitment and post-recruitment processes; upwelling.

\section{INTRODUCTION}

Rates of propagule supply can have large effects on population and community dynamics. This topic has received considerable attention in studies of benthic marine communities, particularly in the past two decades (see Booth and Brosnan [1995] and Caley et al. [1996] for reviews). In rocky intertidal communities, for instance, the abundance and spatial distribution of sessile invertebrate adults may depend primarily on rates of larval settlement when those rates are low (Underwood 1981, Underwood and Denley 1984, Gaines and Roughgarden 1985, Roughgarden 1986, Menge 1991, Underwood and Chapman 1996). Adult size

Manuscript received 13 September 1999; revised 10 July 2000; accepted 28 July 2000.

${ }^{3}$ Present address: Department of Marine Biology, James Cook University, Townsville, Queensland 4811, Australia. structure can be less variable where recruitment events are rare, because single cohorts dominate local populations (Ebert 1983, Ebert and Russell 1988). Conversely, frequent, high settlement can produce oscillations at the neighborhood scale when mortality is strongly density dependent (Gaines and Roughgarden 1985, Roughgarden et al. 1985, Grantham 1997). Even the strength and importance of species interactions among adults can depend on settlement rates (Underwood et al. 1983, Underwood and Denley 1984, Connell 1985, Roughgarden et al. 1988, Menge 1992, Menge et al. 1994, Navarrete and Menge 1996, Robles 1997, Connolly and Roughgarden 1998, 1999a, Dial and Roughgarden 1998). Growing appreciation for the importance of larval supply has prompted benthic ecologists to focus increasingly on the causes of variability in larval supply as explanations for spatial and temporal patterns in population and community structure 
and dynamics. This growing body of studies encompasses rocky intertidal communities (e.g., Roughgarden et al. [1988] in the northeast Pacific, Gaines and Bertness [1992] in the northeast Atlantic), as well as coral reefs (e.g., Hughes et al., in press) and temperate subtidal communities (e.g., Wing et al. 1995, Palma et al. 1999), among others.

Rocky intertidal communities in the northeast Pacific Ocean have been model systems for linking the physical processes regulating larval supply with benthic population and community dynamics (e.g., Gaines and Roughgarden 1985, Ebert and Russell 1988, Roughgarden et al. 1988, Farrell et al. 1991, Alexander and Roughgarden 1996, Grantham 1997, Menge et al. 1997, Connolly and Roughgarden 1998, 1999a). These studies have emphasized the transport of larvae in surface currents produced during upwelling. During the spring and summer, strong equatorward winds, in conjunction with the Coriolis force, cause a surface layer of water to move offshore (Brink 1983). Meroplankton, including the larvae of intertidal invertebrates, become entrained in these offshore-moving currents, and they accumulate at offshore fronts where this water meets the warmer, fresher water of the California Current (Roughgarden et al. 1991, Grantham 1997, Bjorkstedt 1998). When these upwelling-favorable winds relax, the fronts move onshore, depositing larvae near the benthic habitat and facilitating recruitment (Farrell et al. 1991, Roughgarden et al. 1991, Wing et al. 1995, 1998, Miller and Emlet 1997).

Upwelling intensity varies along the coast. Particularly strong upwelling occurs near major headlands, and jets of cold, recently upwelled water frequently extend equatorward and offshore of these upwelling centers (Brink 1983, Rosenfeld et al. 1997). This is generally attributed to an intensification of upwellingfavorable winds that occurs near major headlands (see Brink [1983] for a review). In addition, upwelling intensity varies inversely with the strength of the Coriolis force. Because this force increases as latitude increases, a given equatorward wind stress generates less offshore transport at higher latitudes (Ekman 1905). These oceanographic patterns have led workers to propose hypotheses relating these transport processes to regional-scale variability in recruitment to intertidal communities. For instance, Ebert and Russell (1988) observed that coastal headlands become increasingly prominent as one moves from central California to central Oregon. Reasoning that larvae should be carried away from potential settlement sites in the offshore jets associated with these headlands, they hypothesized that urchin recruitment decreases from central California to central Oregon. In contrast, Roughgarden et al. (1988) proposed that the latitudinal gradient in the Coriolis force causes recruitment of intertidal invertebrates to increase from central California to Oregon and Washington. Empirical tests of these hypotheses also conflict. Ebert and Russell (1988) found that latitudinal variation in the size structure of urchin populations indicates decreasing recruitment with increasing latitude, but only after first accounting for distance south of a major headland in a multiple regression. In contrast, barnacle recruitment increases with latitude within central California (Miller 1992, Grantham 1997). Furthermore, percentage cover of intertidal barnacles and mussels increases with latitude from central California to northern Oregon (Connolly and Roughgarden 1998). However, this gradient takes the form of a transition from a region of lower percentage cover in central and northern California to a region of higher percentage cover in central and northern Oregon, rather than the gradual, monotonic gradient visualized by Roughgarden et al. (1988). Cape Blanco, a major headland in southern Oregon, lies between these two regions. Oceanographic evidence indicates that there is a coincident, marked shift in upwelling at Cape Blanco; this is attributed to the combined effects of a stronger Coriolis force at higher latitudes and the presence of major headlands south of Cape Blanco (Parrish et al. 1981, Bakun and Parrish 1982). As a result, Cape Blanco is considered to bound two oceanographic regions: a region extending north to southern Canada, in which upwelling is weak, and a region extending south to Point Conception, in which upwelling is strong (e.g., U.S. GLOBEC 1994).

In this study we quantified recruitment rates of barnacles and mussels, the dominant sessile invertebrates on temperate rocky shores, from central California to northern Oregon to determine whether (1) recruitment is significantly higher north of Cape Blanco than south of it (Connolly and Roughgarden 1998). In addition, we tested two conflicting hypotheses about latitudinal variability in recruitment south of Cape Blanco: (2) recruitment decreases as latitude increases (Ebert 1983, Ebert and Russell 1988), and (3) recruitment increases as latitude increases (Roughgarden et al. 1988). While a latitudinal gradient in recruitment has been documented for barnacles within central California (Miller 1992, Grantham 1997), other tests of these hypotheses are based on inferences from adult size-frequency distributions or abundances (Ebert and Russell 1988, Connolly and Roughgarden 1998). By directly measuring recruitment over a large scale, we reduce (but do not necessarily eliminate-see Discussion, below) the confounding effects of variation in post-settlement mortality (Barry and Tegner 1989). Further, the large scale of this study allows us to interpret the previous, smaller-scale studies (Ebert and Russell 1988, Miller 1992, Grantham 1997) in a broader geographical context. It also provides a context within which we can interpret regional differences in the processes emphasized by experiments on rocky shores.

\section{Methods}

Study sites (Fig. 1) span the California coast from San Simeon $\left(35.5^{\circ} \mathrm{N}\right)$ to Cape Mendocino $\left(40.4^{\circ} \mathrm{N}\right)$, 


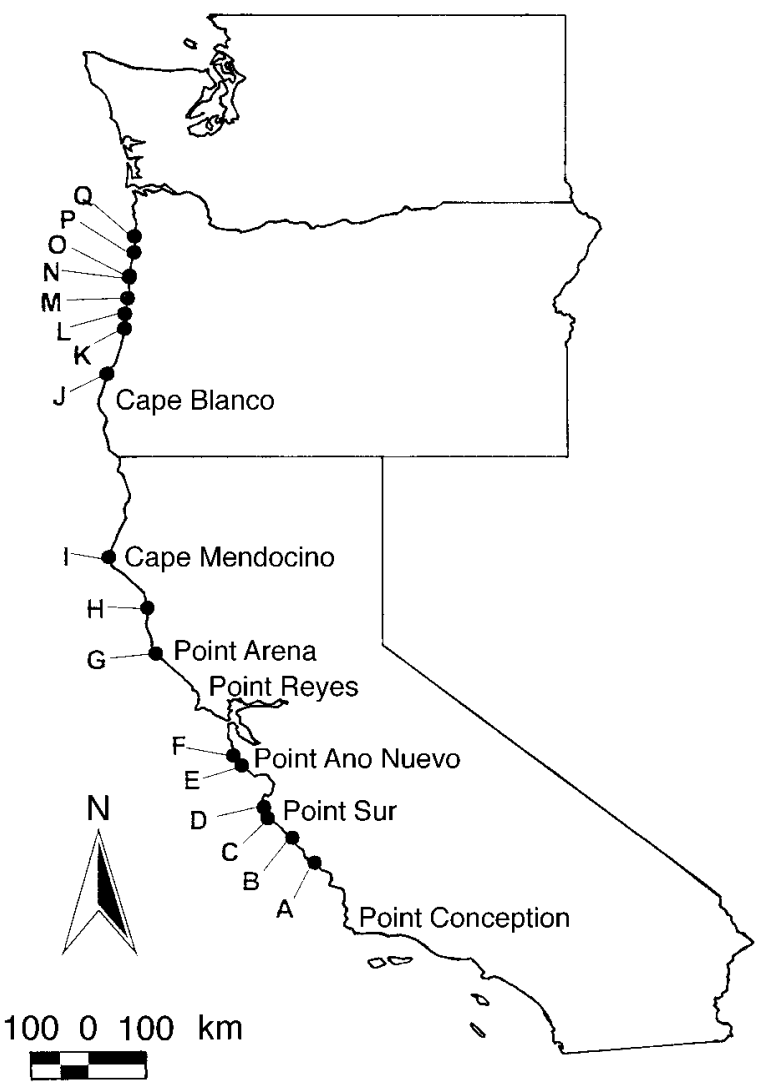

FIG. 1. Map of California and Oregon (USA) showing locations of study sites. The names of major headlands are shown. Sites are indicated by letters as follows: A = San Simeon $\left(35^{\circ} 35^{\prime} \mathrm{N}\right)$; B $=$ Mill Creek $\left(35^{\circ} 58^{\prime} \mathrm{N}\right)$; C $=$ Molera Point $\left(36^{\circ} 17^{\prime} \mathrm{N}\right) ; \mathrm{D}=$ Soberanes Point $\left(36^{\circ} 27^{\prime} \mathrm{N}\right) ; \mathrm{E}=$ Waddell Beach $\left(37^{\circ} 06^{\prime} \mathrm{N}\right) ; \mathrm{F}=$ Pescadero Beach $\left(37^{\circ} 16^{\prime} \mathrm{N}\right)$; $\mathrm{G}=$ Saunders' Reef $\left(38^{\circ} 52^{\prime} \mathrm{N}\right) ; \mathrm{H}=$ Westport $\left(39^{\circ} 36^{\prime} \mathrm{N}\right)$; $\mathrm{I}=$ Devil's Gate $\left(40^{\circ} 24^{\prime} \mathrm{N}\right) ; \mathrm{J}=$ Cape Arago $\left(43^{\circ} 18^{\prime} \mathrm{N}\right)$; K $=$ Florence Jetty $\left(44^{\circ} 01^{\prime} \mathrm{N}\right) ; \mathrm{L}=$ Strawberry Hill $\left(44^{\circ} 15^{\prime}\right.$ $\mathrm{N}) ; \mathrm{M}=$ Seal Rock $\left(44^{\circ} 30^{\prime} \mathrm{N}\right) ; \mathrm{N}=$ Boiler Bay $\left(44^{\circ} 50^{\prime} \mathrm{N}\right)$; $\mathrm{O}=$ Fogarty Creek $\left(44^{\circ} 51^{\prime} \mathrm{N}\right) ; \mathrm{P}=$ Cape Kiwanda $\left(45^{\circ} 13^{\prime}\right.$ $\mathrm{N}) ; \mathrm{Q}=$ Cape Meares $\left(46^{\circ} 28^{\prime} \mathrm{N}\right)$.

and the Oregon coast from Cape Arago $\left(43.4^{\circ} \mathrm{N}\right)$ to Cape Meares $\left(45.5^{\circ} \mathrm{N}\right)$. At monthly intervals, we sampled recruitment in the mid-intertidal (mussel) zone at the most wave-exposed location accessible at each site. Sampling was underway at all sites by May 1996 and ended in September 1997. The California and Oregon sites were part of different ongoing recruitment monitoring projects in their respective regions. Although generally comparable, there were some differences in protocol between these projects. To estimate the potential effect of this difference on our results, we compared the two methods explicitly in June 2000. To maximize our ability to detect any differences between these protocols, we conducted this comparison in central Oregon (Boiler Bay), where recruitment rates were highest. These differences, of course, do not affect the tests for gradients south of Cape Blanco (Hypotheses
2 and 3), since all sites in that region were part of the California project.

Barnacles recruited to styrene plates covered with safety walk tape (3M Company [Saint Paul, Minnesota, USA]; Farrell et al. 1991, Shkedy and Roughgarden 1997, Menge 2000). Stainless-steel bolts secured settlement plates to the substrate. At the California sites, six $5 \times 10 \mathrm{~cm}$ settlement plates were used, while eight $10 \times 10 \mathrm{~cm}$ plates were used in Oregon. In the laboratory we counted barnacle recruits to each settlement plate by inspecting them under dissecting microscopes. Juveniles were identified to genus level because we were unable to distinguish visually between the species Chthamalus dalli and C. fissus (cf. Farrell et al. 1991). Due to the large volume of samples being processed in Oregon as part of ongoing recruitment monitoring, and the difficulty of identifying barnacle cyprids to genus, cyprids were lumped (not identified by taxon) in Oregon. Thus, cyprids are treated as a single, separate category in all analyses. Finally, due to very high recruit densities in Oregon, plates were subsampled to obtain recruit densities, using four $2.5 \times 2.5 \mathrm{~cm}$ subquadrats. All recruitment densities were standardized to an area of $100 \mathrm{~cm}^{2}$. Mussels recruited to plasticmesh dish-scrubbing pads (SOS Tuffy pads [The Clorox Company, Oakland, California, USA]), secured, like settlement plates, with stainless-steel bolts. Again, six mesh pads were deployed at the California sites, and eight at the Oregon sites. Because Mytilus californianus and $M$. trossulus are visually indistinguishable at this stage, mussel recruits to mesh pads (all Mytilus) were also identified to the genus level only (cf. Menge et al. 1994). In California, mussel recruits were counted by opening each mesh pad so that it could be spread flat, and inspecting it under a dissecting microscope. In Oregon, mussel recruits were detached from the mesh by dissolving their byssal attachments in jars of bleach for $5 \mathrm{~min}$, shaking the jar to remove the recruits from the mesh, then pouring the contents through a $53-\mu \mathrm{m}$ sieve. Scans of opened pads showed that no recruits were left attached to the mesh after this process. In both cases, density estimates were obtained by dividing the number of recruits per pad by the area of the pad when opened and spread flat, then standardizing to an area of $100 \mathrm{~cm}^{2}$. Direct comparisons of the two counting methods have shown that there are no differences between their estimates of recruit density (B. A. Menge, unpublished data).

\section{Analysis}

The ideal parametric statistical procedure for the California-Oregon comparison is a repeated-measures analysis of variance, with site nested within region and replicate plates and tuffy pads nested within sites. However, we were unable to find a transformation of these data that clearly met parametric assumptions. (Recruitment rates were approximately normally distributed at Oregon sites during the upwelling season, but there was 
very strong negative skew in other cases: plates with zero recruitment during winter months in Oregon and year-round at many California sites. Thus, transformations we explored tended to normalize among-plate variation in either California or Oregon, but not both simultaneously.) An extensive search of the statistics literature indicated that there is no nonparametric test for repeated measures that permits a nested design. Therefore, we took each site's monthly recruitment rate to be the mean number of recruits per settlement plate or mesh pad, standardized to an area of $100 \mathrm{~cm}^{2}$. An aggregate measurement of recruitment for each site was then calculated by summing the mean monthly recruitment rates across all months for one year. We could then test for differences between regions using a Wilcoxon two-sample test (Sokal and Rohlf 1995). This analysis has much lower power than the nested repeated-measures ANOVA, and thus represents a very conservative test of the hypothesis of higher recruitment in Oregon.

To determine the extent to which regional differences persisted among months, we calculated the magnitude of the difference in recruitment rates on a month-bymonth basis. We calculated asymmetric 95\% confidence limits on this difference by randomization (Manly 1997). For comparison, we estimated upwelling intensity for the two regions from monthly average upwelling indices available from the Pacific Fisheries Environmental Laboratories (National Marine Fisheries Service, Pacific Grove, California, USA). ${ }^{4}$ As an estimate for central and northern Oregon, we used indices from $45^{\circ} \mathrm{N}$, the station offshore of Oregon that is north of the oceanographic boundary at Cape Blanco (the other Oregon station, at $42^{\circ} \mathrm{N}$, is south of it). As an estimate for the central and northern California region, we averaged upwelling indices from stations at $36^{\circ} \mathrm{N}$ and $39^{\circ} \mathrm{N}$, the two stations offshore of central and northern California.

Upwelling indices allow us to determine roughly when the transition from upwelling-favorable to downwelling-favorable conditions occurred in the two regions. Existing theory that links larval transport processes to intertidal population and community dynamics models upwelling conditions (Alexander and Roughgarden 1996, Connolly and Roughgarden 1998, $1999 a$ ), since most reproduction and recruitment in these species occurs during or near upwelling season (Hines 1976, Strathmann 1987, Miller 1992). Thus, the rationale underlying the hypothesis being tested is most appropriate to the upwelling season, when sustained periods of upwelling, punctuated by relaxation events, occur. In this regard, it is important to recognize that monthly upwelling indices are averages. Conditions rarely shift abruptly from strongly upwelling favorable to strongly downwelling favorable. Rather, spring and fall transitions, when monthly average indices are near

\footnotetext{
${ }^{4}$ URL: 〈http://www.pfeg.noaa.gov〉
}

zero, are periods during which periods of upwellingfavorable conditions are interspersed with periods of downwelling-favorable conditions. These conditions, too, should favor recruitment where upwelling indices are lower, if our hypothesis is correct: transitions from upwelling to downwelling-favorable conditions should carry larvae shoreward much as shorter-term relaxation events do during upwelling season.

For month-by-month comparisons, it is also important to remain aware of the appropriate spatial and temporal scale on which to relate upwelling and recruitment. Recruitment rate is a function of (1) net rates of larval production, and (2) the proportion of those larvae that successfully recruit to the benthic habitat. The models underpinning our hypothesis indicate that, proximately, upwelling should influence (2): weaker upwelling leads to a higher proportion of larvae successfully returning to the benthic habitat. Ultimately, however, this leads to higher adult densities and thus influences (1): more adults lead to higher net larval production. Thus, because upwelling is consistently weaker in Oregon than in central and northern California, we expect recruitment rates, like adult abundances (Connolly and Roughgarden 1998), to be, on average, higher north of Cape Blanco. Changes over time in the magnitude of recruitment differences between regions would be influenced by per capita larval production as well as larval transport (e.g., when very little larval reproduction is occurring, any differences in recruitment rates will be small). Nevertheless, if overall, persistent differences in upwelling explain recruitment differences, then the recruitment differences should be persistent, particularly during upwelling season; that is, they should not be caused by one or a few large recruitment pulses in Oregon.

To test for monotonic gradients in recruitment within central and northern California, we obtained cumulative annual recruitment rates for each site as for the regional comparisons. We then tested for monotonic trends in recruitment using rank correlation (Kendall's $\tau)$. Because Ebert and Russell (1988) found a latitudinal gradient only after accounting for distance south of a major headland in a multiple regression, we also calculated partial correlations, using distance south of a major headland as a covariate (Daniel 1990).

The study period included the onset of El Niño conditions in the Northeast Pacific in May 1997. This coincided with major changes in offshore transport (Liu et al. 1998) and barnacle recruitment (Connolly and Roughgarden 1999b). Therefore, we calculated annual recruitment for each site based on the first 12 mo of the study (May 1996-April 1997), avoiding the El Niño period. However, we checked the robustness of our results by repeating the analyses using the last 12 mo instead (October 1996-September 1997). For brevity, we report only the results of the analysis of the first 12 mo, except where the significance of the results was different for the last 12 mo. 

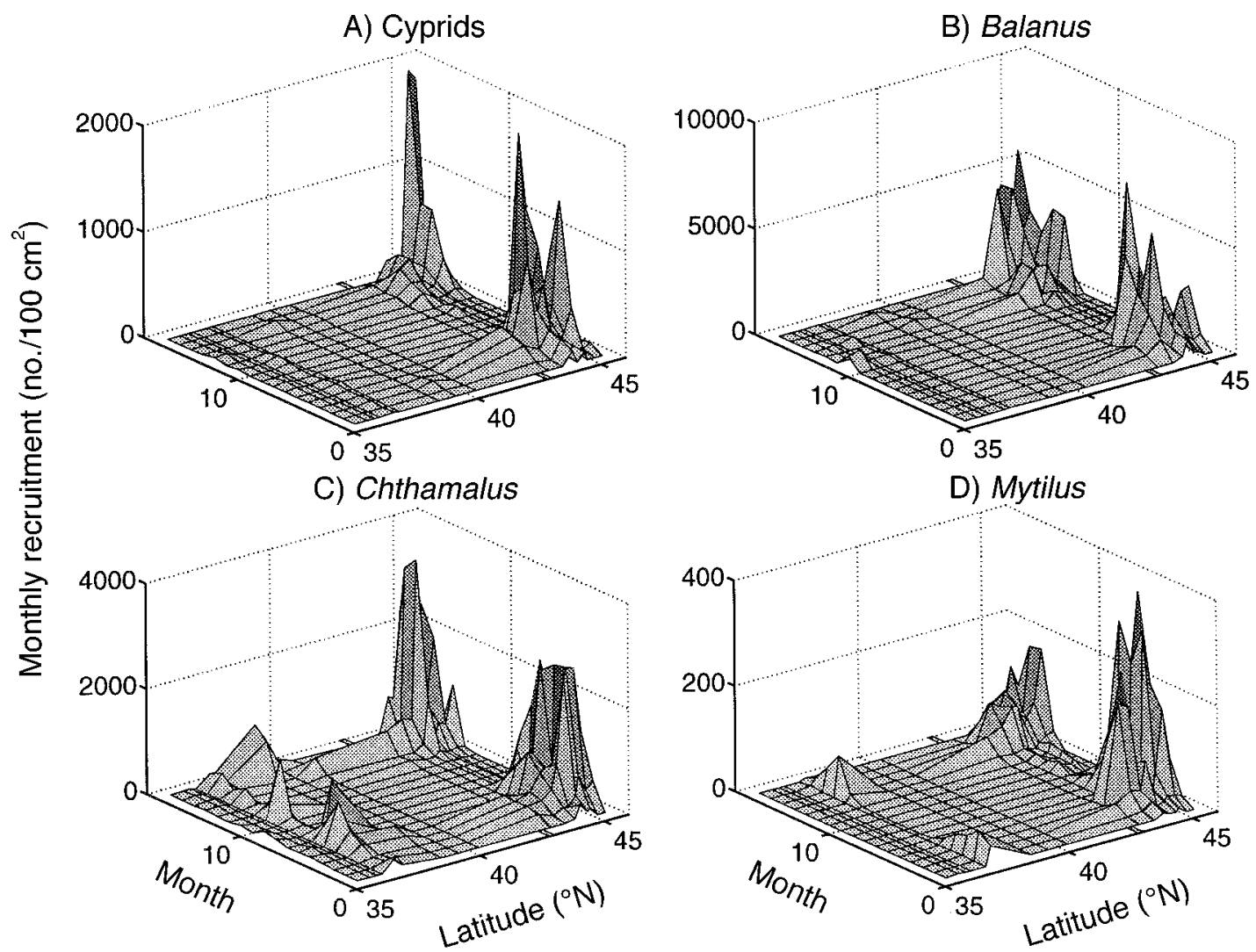

FIG. 2. Recruitment as a function of time and latitude for (A) cyprids (all barnacles combined), (B) Balanus, (C) Chthamalus, and (D) Mytilus. Each point represents the mean across all replicates for that particular site and month. Time runs from May 1996 to September 1997. In all plots, the location of Cape Blanco (southern Oregon, USA) is marked with a narrow bar extending beyond the beginning and end of the time series at $42.9^{\circ} \mathrm{N}$.

Occasionally, hazardous surf, wildfire, or cold-room malfunction prevented access to sites or caused samples to be lost. With the exception of a cold-room malfunction in which California samples for August 1996 were lost, this occurred during late fall and winter, when recruitment rates were very low or zero throughout the study region (see Results, below). For calculation of cumulative annual recruitment, we estimated recruitment during such months by linear interpolation (the average of the site's mean recruitment from the previous and subsequent months) for the California sites. To ensure that our test for higher recruitment north of Cape Blanco was as conservative as possible, we assumed that recruitment was zero at any Oregon site for any month during which that site was inaccessible. To verify that statistically significant results were not the result of interpolated recruitment rates, we checked the robustness of our results by retesting all significant differences without using interpolated data. This involved removing August 1996 data from the calculation of annual recruitment in 1996, due to the cold-room malfunction, and excluding all sites missing data from any other month. Thus, of the California sites, Westport and Molera Point were excluded from these analyses. Of the Oregon sites, Cape Arago, Flor- ence Jetty, Cape Kiwanda, and Cape Arago were excluded. In addition, Fogarty Creek was excluded for barnacle cyprids. For the month-by-month comparisons, interpolation was unnecessary: for any given month, we simply used the sites from which recruitment data were obtained. Thus, we did not estimate recruitment differences for August 1996 or January 1997, since data were unavailable for California and Oregon, respectively, during those months.

\section{RESULTS}

Time-series plots of recruitment vs. time and latitude for the entire 17-mo study are presented in Fig. 2. Annual recruitment (calculated from the first $12 \mathrm{mo}$ ) is plotted vs. latitude in Fig. 3. Recruitment rates of barnacle cyprids (all species combined), Chthamalus juveniles, Balanus juveniles, and Mytilus were all significantly higher north of Cape Blanco than south of it (cyprids: $U=72, P<0.001$; Balanus: $U=72, P<$ 0.001; Chthamalus: $U=66, P<0.01$; Mytilus: $U=$ $71, P<0.001)$. These differences were very large. Median annual recruitment in Oregon was higher than in California by a factor of 50 for barnacle cyprids, a factor of 38 for Balanus juveniles, a factor of 19 for Chthamalus juveniles, and a factor of 98 for Mytilus. 


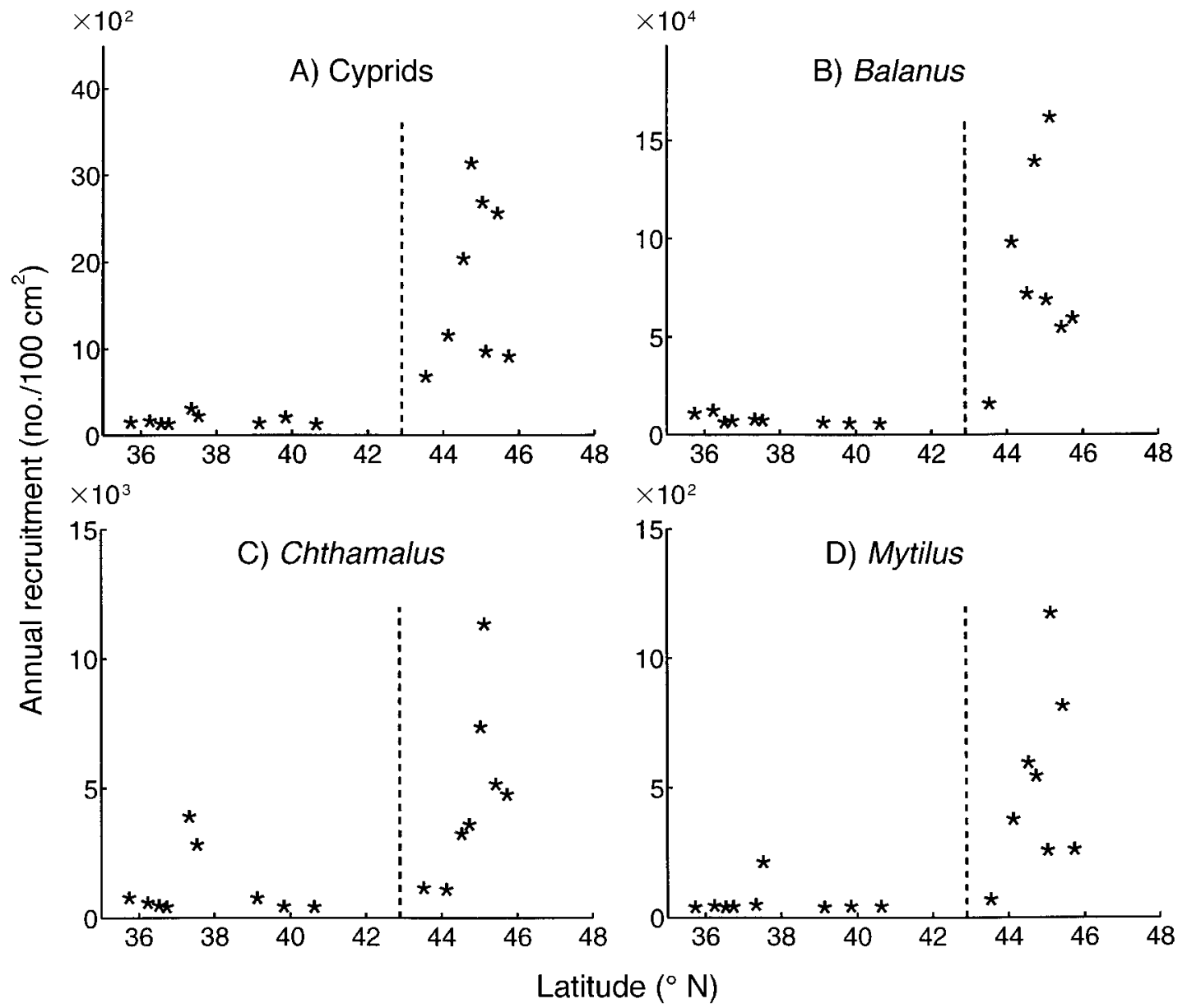

FIG. 3. Annual recruitment as a function of latitude for (A) cyprids, (B) Balanus, (C) Chthamalus, and (D) Mytilus. In all plots, a dashed vertical line marks the location of Cape Blanco (southern Oregon, USA).

For cyprids and Balanus juveniles, annual recruitment at every site in Oregon was higher than at any site in California (Fig. 3A and B). This was true for Mytilus as well, with one exception: recruitment at Pescadero Beach in California was higher than recruitment at Cape Arago in Oregon (Fig. 3D).

Month-by-month median recruitment differences between California and Oregon, with approximate 95\% confidence intervals, are plotted in Fig. 4 for the entire 17 -mo study period. Differences $>0$ indicate higher recruitment in Oregon, while differences $<0$ indicate higher recruitment in California. Confidence limits on these monthly differences obtained by randomization approximate a two-tailed test for significant differences in recruitment between the two regions (at $\alpha=0.05$ ). Recruitment was never significantly higher in California, for any taxon.

Mean monthly upwelling index was always lower in central and northern Oregon than in central and northern California (Fig. 5). Each month had one of three different combinations of upwelling/downwelling conditions: (1) upwelling favorable, weaker in Oregon than in California (May-September 1996 and May-August 1997); (2) downwelling favorable in Oregon, upwelling favorable in California (October-November 1996 and February-April 1997); (3) downwelling favorable in both regions, with stronger downwelling in Oregon than in California (December 1996-January 1997). For months in which scenario (1) holds-weaker upwelling in Oregon than in California-estimated recruitment differences indicate higher recruitment in Oregon. These differences are individually significant at $\alpha=$ 0.05 in 28 of 32 comparisons (Fig. 4, months 1-5 and 13-16). October 1996, April 1997, and September 1997 were transitional months. That is, they fell immediately prior to or following upwelling-favorable months, monthly average upwelling index in Oregon was near zero ( $>-5$ in each case), and daily upwelling indices from these months indicated substantial shifting between upwelling-favorable and downwelling-favorable conditions. In October 1996, 19 of $31 \mathrm{~d}$ were upwelling favorable; in April 1997, 12 of $30 \mathrm{~d}$ were upwelling favorable; in September 1997, 15 of 30 d were upwelling favorable (Pacific Fisheries Environmental 


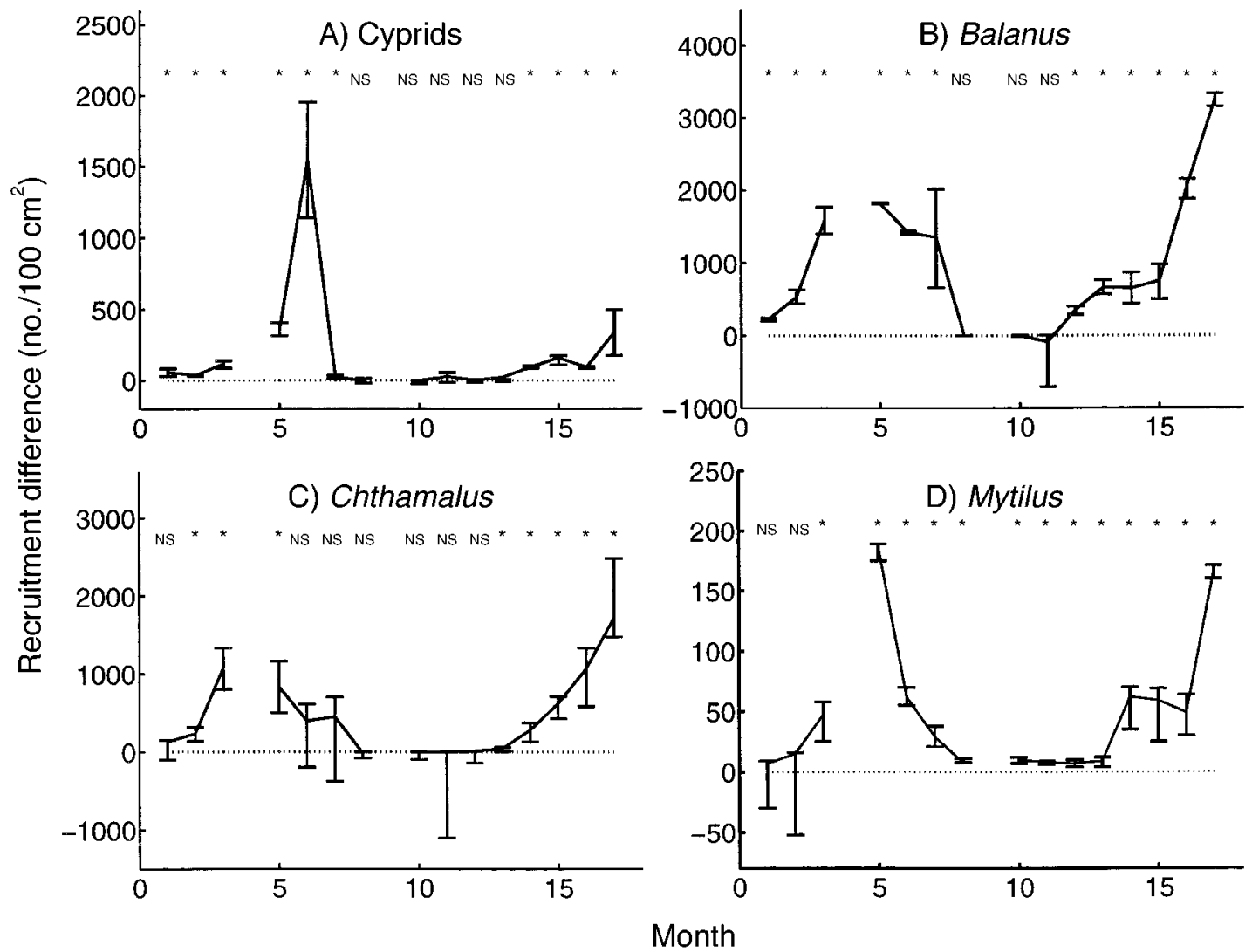

FIG. 4. Estimated differences in median monthly recruitment at sites north vs. south of Cape Blanco (Oregon, USA) for (A) cyprids, (B) Balanus, (C) Chthamalus, and (D) Mytilus. Median differences are shown with the line connecting successive months; error bars represent approximate 95\% confidence intervals, calculated according to the resampling method described by Manly (1997). Values $>0$ indicate higher recruitment in Oregon; values $<0$ indicate higher recruitment in California. Asterisks indicate that the corresponding month's recruitment difference is individually significant at $\alpha=0.05$, using the asymmetric confidence intervals as a two-tailed significance test; "NS" indicates that differences were not significant by this criterion.

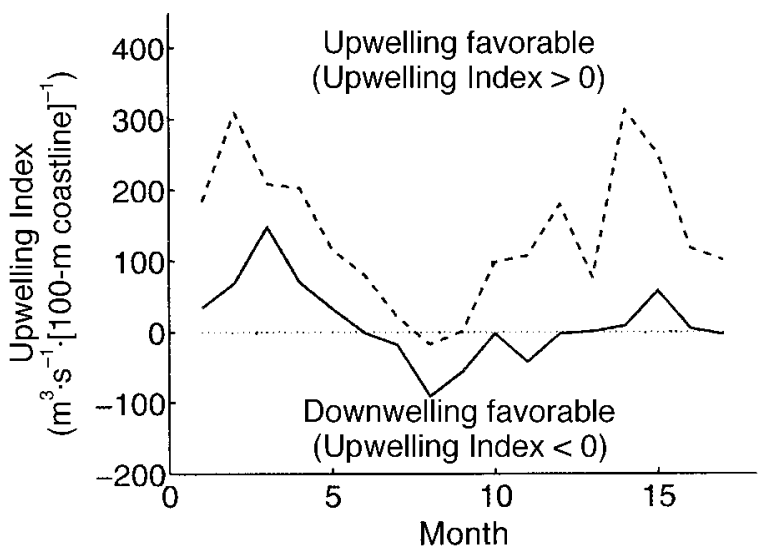

FIG. 5. Upwelling indices for the two upwelling regions. Upwelling index for central/northern Oregon is plotted with a solid line; upwelling index for central/northern California is plotted with a dashed line. A dotted line marks the shift from upwelling-favorable to downwelling-favorable conditions.
Laboratories; see footnote 4). During those months, recruitment differences also indicated higher rates in Oregon in every case. These differences were individually significant in 9 of 12 comparisons (Fig. 4: months 6,12 , and 17). During the remaining months, recruitment differences tended to be small (Fig. 4). This is not surprising: there is very little reproduction in these species during late fall and winter (Hines 1976, Strathmann 1987, Miller 1992), and thus total recruitment was low during this period (Fig. 2).

Comparison of the two settlement plate and counting protocols for barnacles yielded virtually identical recruitment estimates. From five recovered $5 \times 10 \mathrm{~cm}$ plates, and eight recovered $10 \times 10 \mathrm{~cm}$ plates, we found no significant differences in recruitment for either Chthamalus $(F=0.077, P=0.79$, df $=1,11)$ or Balanus $(F=0.029, P=0.87$, df $=1,11)$. Monitoring protocol explained $<1 \%$ of the among-plate variation in recruitment ( $r^{2}<0.01$ for both taxa). Recruitment rates were approximately normally distributed for the site where the comparison was conducted (Boiler Bay), so analysis of variance was appropriate.

Within California, recruitment was not significantly 
TABLE 1. Correlations of annual recruitment with latitude within California.

\begin{tabular}{lcc}
\hline \hline & \multicolumn{2}{c}{ Correlation coefficient, $\tau$} \\
\cline { 2 - 3 } \multicolumn{1}{c}{ Taxon } & Full & Partial \\
cyprids & -0.05 & correlation \\
\hline Balanus & $-0.61^{*}$ & -0.28 \\
Chthamalus & -0.33 & $-0.61^{*}$ \\
Mytilus & 0.17 & -0.35 \\
\hline
\end{tabular}

Note: In partial correlations, distance south of a major headland was the third variable (Ebert and Russell 1988).

$* P<0.05$.

correlated with latitude for barnacle cyprids, Chthamalus juveniles, or Mytilus (Fig. 3, Table 1). While annual recruitment of Balanus does decrease significantly as latitude increases (Fig. 3, Table 1), this gradient is not significant when annual recruitment is calculated for the last 12 mo of the study instead of the first 12 mo $(\tau=-0.03, P>0.5)$. Accounting for distance south of a major headland in a partial correlation does not change the results (Table 1).

When data were analyzed without interpolated recruitment rates (see Methods, above), recruitment was still significantly higher in Oregon than in California for all taxa (cyprids, $U=21, P<0.01$; Balanus, $U=$ 28, $P<0.01$; Chthamalus, $U=25, P<0.05$; Mytilus, $U=28, P<0.01)$. These differences tended to be even larger in magnitude than under the original analysis (not surprising, given the extremely conservative method of interpolation we used). Median annual recruitment in Oregon was higher than in California by a factor of 185 for barnacle cyprids, a factor of 153 for Balanus juveniles, a factor of 17 for Chthamalus juveniles, and a factor of 275 for Mytilus. Again, the transition closely resembles a stepcline: for all genera except Chthamalus, all Oregon sites had higher recruitment than all California sites. However, within central and northern California, the only significant trend-decreasing Balanus recruitment with increasing latitude-becomes nonsignificant $(\tau=-0.53, P>$ 0.1 ). This analysis confirms that the overall differences between California and Oregon are robust with respect to interpolation method. However, we are unable to confirm that the one significant within-California gradient is similarly robust.

\section{DISCUSSION}

\section{Large-scale patterns}

A marked transition in recruitment rates occurred near Cape Blanco in southern Oregon (USA). Differences in recruitment rates north and south of this headland were highly significant and very large for all taxa. Further, for both cyprids and Balanus juveniles, every site north of Cape Blanco had higher recruitment than any site in California, despite the use of an extremely conservative interpolation method. This shift coincides with a transition in benthic community structure (Connolly and Roughgarden 1998). Month-by-month estimates of the magnitude of recruitment differences indicated that these differences persisted throughout upwelling seasons and transitional months for all taxa (Fig. 4).

Cape Blanco also divides regions of the northeast Pacific within which studies of rocky shores have historically emphasized different ecological processes. North of Cape Blanco in Oregon and Washington, zonation among mussels and barnacles is often pronounced, and processes regulating access to free space among these species, such as competition, predation, and disturbance, are intense and important agents of community structure. By contrast, in central and northern California, zonation among barnacles and mussels is often weak, species interactions tend to have smaller effects on community structure, and studies have emphasized rates of larval settlement as major determinants of spatial and temporal patterns in population and community structure. For instance, sea star removals have dramatic effects on space allocation between mussels and their competitors in Oregon and Washington, while effects in central California are much weaker (Paine 1974, Menge et al. 1994; J. S. Pearse, unpublished data). Predator exclusions can also have dramatic effects on allocation of space among Balanus and Chthamalus in the Pacific Northwest (e.g., Dayton 1971); experiments in central California have found much smaller effects (T. M. Farrell, unpublished data). See Connolly and Roughgarden (1999a) for detailed comparison of these studies. In addition, Wootton $(1993,1994)$ found that eliminating bird predation on the gooseneck barnacle Pollicipes polymerus led to competition-induced decreases in Mytilus abundance in Washington, while Meese (1993), working in northern California, found no change in Mytilus abundance associated with such exclusions.

Connell (1985) proposed that processes regulating access to space should be more important where recruitment rates are high than when they are low. Conversely, processes regulating larval supply should be more important determinants of community structure where recruitment rates are low. The concordance of regional differences in the results of experimental studies and the transition in recruitment documented here is consistent with that hypothesis. In particular, it supports the argument that differences in recruitment rates are a major cause of differences in the structure of intertidal invertebrate communities in central California and the Pacific Northwest (Roughgarden et al. 1988). Moreover, the concordance of marked transitions in upwelling intensity, recruitment, and community structure supports the hypothesis that regional differences in upwelling intensity are a major cause of the shift in community structure (Roughgarden et al. 1988, Connolly and Roughgarden 1998).

Although the transitions in recruitment coincide with 
an overall transition in benthic community structure (more scarce free space and higher sessile invertebrate cover north of Cape Blanco), comparisons of recruitment and percentage cover transitions for individual taxa suggest that higher recruitment disproportionately benefits competitive dominants. Specifically, the mussel Mytilus occupies more space in the middle zone in Oregon, where it is competitively dominant, but the competitively subordinate barnacles Balanus and Chthamalus do not (Connolly and Roughgarden 1998). This is consistent with conceptual and mathematical models of rocky-shore communities. These models predict more intense competition where recruitment is facilitated (Menge and Sutherland 1987, Roughgarden et al. 1988, Connolly and Roughgarden 1998, 1999a). High zone patterns are also consistent with these models: the competitively dominant Balanus occupies more space in Oregon, but the subordinate Chthamalus does not. Indeed, Chthamalus actually occupies more space in California (Connolly and Roughgarden 1998), despite having markedly higher recruitment in Oregon (Fig. 3)! This last point assumes that the transitions in recruitment documented here are reflected, at least qualitatively, by transitions in the high zone. We suspect, but cannot confirm, that this assumption is reasonable for the present study, given the magnitude of the mid-zone transitions in recruitment and the absence of a compelling reason to expect this transition to be reversed or eliminated as a function of tidal height.

In one respect, however, our findings differ from theoretical prediction. Specifically, higher recruitment of Chthamalus in Oregon differs from the prediction of a mathematical model of barnacle competition in the intertidal zone in which recruitment of a competitive subordinate is lower where upwelling is weaker (Connolly and Roughgarden 1998). This occurs because weaker upwelling facilitates recruitment of the dominant (assumed to represent Balanus) and thus reduces subordinate (i.e., Chthamalus) adult population sizes, a direct effect of competition. Indirectly, reduced subordinate abundances lead to lower net larval production, and thus lower net recruitment of the subordinate, even though recruitment of individual larvae is facilitated by the more favorable oceanographic conditions (see Connolly and Roughgarden [1998] for additional explanation).

The fact that Chthamalus recruitment is actually higher where upwelling is weak, in contrast to the subordinate in the model community, suggests that the model overestimates this indirect effect. One possible explanation is predator preference for Balanus over Chthamalus (Paine 1981, Navarrete 1996, Berlow 1997) in the middle and low zones. If predation is more intense where upwelling is weak (cf. Connolly and Roughgarden 1999a), and predators prefer Balanus over Chthamalus (Paine 1981, Navarrete 1996, Berlow 1997), then the gradient of increasing competitive effects with decreasing upwelling would be weaker below than inside the barnacle zone. This is consistent with the observation that Chthamalus occupies significantly more space in California than Oregon in the barnacle zone, but not in the mussel zone (Connolly and Roughgarden 1998). Alternatively, a pure competitive hierarchy may not be a good approximation for the Balanus-Chthamalus interaction when densities are high (Grantham 1997, Menge 2000; also see Dungan 1985). Under either scenario, the population-level effect of Balanus on Chthamalus would be reduced where upwelling is weak, allowing Chthamalus to benefit more from weak upwelling than does the subordinate population in the model.

It is important to note that this does not affect the theoretical expectation of more intense competition where upwelling is weak. Measurements of interaction strength can be derived analytically from the competition model described above, and these measurements decrease in magnitude as upwelling increases, even when the effect of competition on subordinate stock sizes is eliminated from the model (Connolly and Roughgarden 1999a). Further, conceptual models of rockyshore communities ignore stock-recruitment effects entirely and assume that recruitment rates are positively correlated among species, as they appear to be here. These models also predict that the intensity of competition increases as recruitment rates increase (Menge and Sutherland 1987, Roughgarden et al. 1988).

Not surprisingly, every month during which conditions were, on average, upwelling-favorable in both regions, upwelling was weaker in Oregon than in California (Fig. 5). During those months, regional differences in monthly recruitment indicated higher recruitment in Oregon for all taxa and every month; these differences were individually significant at $\alpha=0.05$ in 28 of 32 cases. The same pattern was observed during the additional months we characterized as transitional. Regional differences indicated higher recruitment in Oregon for each taxon during all three of these months, and these differences were individually significant at $\alpha=0.05$ in 9 of 12 cases. The fact that recruitment rates are so consistently higher in Oregon during this period is remarkable, given the highly episodic nature of recruitment, the mesoscale variability in the California Current, and the potential for at least minor variation in the seasonal timing of onset and/or cessation of reproduction in these species.

During the remaining months, recruitment differences were much smaller (Fig. 4). This is not surprising, since very little reproduction occurs in the late fall and winter (Hines 1976, Strathmann 1987, Miller 1992), and recruitment rates were low (Fig. 2). Of 16 taxon/month estimated differences, 8 were higher in Oregon (6 of which were significant), 7 were higher in California (none of which were significant), and, in one case, the estimated difference was exactly zero.

In a few cases, approximate $95 \%$ confidence intervals were highly asymmetric, with the median estimated difference closer to the upper confidence limit (Fig. 4). For 
Balanus, this occurred in March 1997 (month 11 in Fig. 4B), and coincided with an apparent recruitment pulse at San Simeon and Mill Creek. This pulse was reflected weakly at other central California sites, but it was absent from northern California (Fig. 2B). For Chthamalus, this occurred in October 1996, November 1996, and March 1997 (months 6, 7, and 11 in Fig. 4C), and coincided with high recruitment at Ano Nuevo and Pescadero Beach, relative to other sites in California (Fig. 2C). For Mytilus, asymmetric confidence limits in the study's first two months coincide with high recruitment at Pescadero Beach, relative to other California sites (Fig. 2D). Were these localized pulses caused by alongshore variation in the timing of onset of reproduction in these species (e.g., March 1997 recruitment of Balanus)? Were they due to short-term, mesoscale variation in the California Current (e.g., relatively high recruitment of Mytilus and Chthamalus at Pescadero and Ano Nuevo)? Or were other factors responsible? Unfortunately, the broad geographical scope of our study, while appropriate and necessary for characterizing large-scale patterns, affords limited resolution at the scale of individual sites, relative to studies that focus on one or a few locations. However, these patterns suggest fruitful locations on which future work addressing mesoscale and short-term patterns might focus.

\section{Patterns within California}

In contrast to the regional pattern, monotonic recruitment gradients within California, if they exist, are small. Only Balanus recruitment varies significantly with latitude in our study, and three facts suggest that even this gradient may not hold during all, or even most, years. First, when the analysis is conducted on the last 12 mo rather than the first 12 mo, the gradient disappears (see Results, above). This is because the northern California sites showed the largest increases in recruitment during the $1997 \mathrm{El} \mathrm{Niño} \mathrm{(Connolly} \mathrm{and}$ Roughgarden 1999b). Second, the gradient is nonsignificant when the analysis is conducted without interpolation (i.e., excluding August 1996 and the sites at Westport and Molera Point). Third, the gradient is largely driven by very high recruitment in March 1997 at the southernmost sites (month 11 in Fig. 2B). If we exclude this month from the calculation of annual recruitment, the gradient disappears (results not shown). Thus, the persistence of the latitudinal gradient depends upon the March recruitment event at the southern sites being comparable in magnitude every year. This differs greatly from the California-Oregon comparison, for which recruitment differences are both more consistent across months and larger overall for all genera (Figs. 3 and 4).

If there is a large change in recruitment associated with a transition in upwelling at Cape Blanco, why are there no large gradients within California? Oceanographic evidence suggests that differences in upwelling within central and northern California are small, rel- ative to differences between California and Oregon. Bakun and Parrish (1982) report the average summer coastal-temperature anomaly (i.e., the difference between the sea-surface temperature at the coast and the average temperature of offshore waters at the same latitude) for the northeast Pacific. Cold anomalies at the coast indicate upwelling. They found that this anomaly changed markedly near Cape Blanco: cold anomalies were $3-5^{\circ} \mathrm{C}$ smaller in central and northern Oregon than they were in northern California. By contrast, this anomaly varied much more gradually within central and northern California, differing by $<2^{\circ} \mathrm{C}$ between Point Conception and the California-Oregon border. In addition, the relative strengths of upwelling vary seasonally within northern and central California; for instance, rates of offshore transport are higher in northern California during the summer but higher in central California in the spring and fall (Parrish et al. 1981). (In contrast, Parrish et al. [1981] found that offshore transport is weaker north of Cape Blanco than south of it throughout the year.) Thus, latitudinal trends in recruitment within central and northern California, if they exist, may be sufficiently weak or seasonally variable that they are obscured by mesoscale processes, such as eddies (Roughgarden et al. 1996), upwelling shadows (Graham et al. 1992, Wing et al. 1998), or offshore kelp forests (Gaines and Roughgarden 1987).

While recruitment did not vary monotonically within California, with the possible exception of Balanus, the data suggest that previous studies indicating either increasing (Miller 1992, Grantham 1997) or decreasing (Ebert and Russell 1988) recruitment with latitude can be synthesized. The prior studies focused on different regions of the coast, both of which are encompassed by our study. Ebert and Russell (1988) detected a significant decline in recruitment with latitude in a multiple regression that included sites between Soberanes Point, $36^{\circ} \mathrm{N}$, and Cape Blanco, $42.9^{\circ} \mathrm{N}$ (see Fig. 1). We computed partial correlations for our study using just the sites within that region, treating distance south of the nearest headland as a covariate, as they did. We find that all correlations are negative, suggesting decreasing recruitment with increasing latitude within this region (Table 2). By contrast, Miller (1992) and Grantham (1997) found increasing recruitment with latitude between San Francisco (just south of Point Reyes), $37.8^{\circ} \mathrm{N}$, and Point Sur, $36.3^{\circ} \mathrm{N}$ (see Fig. 1). We computed partial correlations for our sites in this region (including Molera Point, which is $<2 \mathrm{~km}$ south of Point Sur), and we found that all correlations were positive, suggesting increasing recruitment with increasing latitude in this region (Table 2).

Notice that both of these gradients overlap a region extending roughly from San Francisco, $37.8^{\circ} \mathrm{N}$, to Monterey Bay (the large bay between Point Año Nuevo and Point Sur), $36.8^{\circ} \mathrm{N}$ (see Fig. 1). The trends apparent here (Fig. 3, Table 2), as well as gradients detected in previous studies (Ebert and Russell 1988, Miller 1992, 
TABle 2. Partial correlations of recruitment with latitude.

\begin{tabular}{lcc}
\hline \hline \multirow{2}{*}{ Genus } & \multicolumn{2}{c}{ Correlation coefficient, $\tau$} \\
\cline { 2 - 3 } \multicolumn{1}{c}{$\begin{array}{c}\text { Cape Blanco- } \\
\text { Soberanes Point }\end{array}$} & $\begin{array}{c}\text { San Francisco- } \\
\text { Point Sur }\end{array}$ \\
\hline Cyprids & -0.33 & 0.70 \\
Balanus & -0.33 & 0.70 \\
Chthamalus & -0.47 & 0.43 \\
Mytilus & -0.08 & 1.00 \\
\hline
\end{tabular}

Notes: Correlation coefficients in the second column are computed using only sites in the region studied by Ebert and Russell (1988), and correlation coefficients in the third column are computed using only sites in the region studied by Miller (1992) and Grantham (1997). Because the hypotheses corresponding to these statistics were not formulated a priori, significance levels are not reported.

Grantham 1997), are consistent with the hypothesis that recruitment tends to be higher in this region than either north or south of it. Inspection of satellite imagery of sea-surface temperatures suggests two oceanographic features that may promote this higher recruitment. First, a jet of cold water extending south from Point Reyes appears to trap a mass of warm water near the coast between San Francisco and Point Año Nuevo, causing relatively high nearshore retention of water (and thus potentially larvae) in this region (Parker 1996; J. M. Steger, F. W. Schwing, C. A. Collins, L. K. Rosenfeld, N. Garfield, and E. Gezgin, unpublished manuscript). Indeed, Wing et al. (1998) documented pronounced nearshore retention of larvae between San Francisco and Point Reyes, a phenomenon they attribute to this mechanism. Whether these high larval concentrations persist between San Francisco and Point Año Nuevo is unconfirmed, however. Second, between Point Año Nuevo and Monterey Bay, upwelling fronts (and thus potentially larvae) are maintained relatively close to shore by a persistent onshore meander in the California Current (Schwing et al. 1991, Parker 1996, Rosenfeld et al. 1997).

\section{Assessing potential causes}

The effects of recruitment on population and community dynamics in the northeast Pacific have been documented in numerous experimental studies, each of which focus on one or a few nearby sites. An important contribution of the present study is the characterization of the regional context within which differences among these studies can be interpreted. In addition, as we have noted, the patterns are consistent with the hypothesis that a marked shift in upwelling near Cape Blanco is a major cause of the transition in recruitment. However, as in any broad-scale, observational study, care must be taken when attributing the observed patterns (transitions in recruitment rates) to putative causes (such as a transition in upwelling intensity). That is particularly true in this case, since a transition in recruitment may well have multiple causes. While we cannot present a definitive evaluation of all possible causes, we can offer a preliminary assessment of several particularly plausible ones, and describe how the roles of these and other alternatives might be more conclusively evaluated in future work.

Recruitment rates are a composite measurement of larval settlement and early post-settlement mortality. Thus, it is theoretically possible that all or part of the transition in recruitment rates is due to higher postsettlement mortality south of Cape Blanco, rather than higher rates of larval supply. We view this possibility as unlikely. Coastal fog is common in central and northern California and tends to coincide with extreme low tides in the spring and summer, and these low tides occur earlier in the morning in California than in Oregon. These factors should make desiccation stress unusually mild in California (Foster et al. 1988). Conversely, extreme low tides in the fall and winter occur earlier in the evening in California than in Oregon, reducing exposure during cold temperature extremes as well (Foster et al. 1988). Further, mortality rates increase as density increases (e.g., Gaines and Roughgarden 1985). Since free space is scarcer in Oregon than it is in California (Connolly and Roughgarden 1998), this, too, should tend to make mortality rates lower in California. Thus, we suspect that post-settlement mortality rates are higher, not lower, in Oregon. This is consistent with existing data for barnacles, which indicate markedly higher juvenile mortality in Oregon. In central California, measurements of mortality rates for barnacle recruits (including Balanus and Chthamalus) average 10-20\% per month at each of five sites in central California (Gaines and Roughgarden 1985, Grantham 1997). By contrast, juvenile mortality rates range from $30 \%$ to $100 \%$ per month at three sites in central Oregon (Sanford 1999; R. B. Emlet, unpublished data). Higher post-settlement mortality in Oregon is also suggested by the fact that the transition in recruitment of barnacle cyprids documented here is larger in magnitude than the transitions in juvenile recruitment of either Balanus or Chthamalus.

Within California, intense predation on barnacle cyprids by juvenile rockfish (Sebastes) in kelp forests can substantially affect recruitment, with sites inshore of kelp beds experiencing much lower settlement rates than nearby sites without them (Gaines and Roughgarden 1987). Given that Macrocystis is common in the nearshore waters of central California, it is reasonable to suspect that recruitment patterns documented here are caused by regional differences in Macrocystis abundance and thus rockfish predation. However, when the data are reanalyzed, excluding the four sites with offshore Macrocystis stands, recruitment differences remain significant (cyprids and Balanus juveniles, $U$ $=40, P<0.01$; Chthamalus juveniles, $U=34, P<$ 0.05; Mytilus, $U=39, P<0.01$ ), despite the reduced power associated with eliminating nearly half of the California sites.

Differences in food availability for adults or larvae 
might also affect recruitment rates. More productive surf-zone waters could provide more food to adults, leading to higher rates of per capita larval production and thus higher rates of recruitment. Higher productivity between the coast and offshore upwelling fronts could increase larval growth rates and/or reduce the risk of starvation (though it might also be associated with higher predation). Higher rates of per capita larval production north of Cape Blanco are certainly a possibility. However, we doubt that this, if it exists, is the major cause of the transition in recruitment rates. The effect of per capita larval production on recruitment rates occurs through its effect on larval population size. For instance, even a doubling of per capita larval production would lead to a doubling of larval supply, a relatively small difference compared to the 1-2 orders of magnitude recruitment differences documented here. Further, preliminary work in Oregon suggests that large between-site differences in productivity do not translate into consistent differences in barnacle or mussel recruitment rates (B. A. Menge, unpublished data). Thus, regional differences in surf-zone productivity would probably have to be very large to contribute substantially to the transitions in recruitment.

If the productivity of the planktonic habitat is higher north of Cape Blanco, larval mortality rates might be lower, or maturation rates higher, than south of Cape Blanco. To our knowledge, such regional differences in larval growth or mortality rates have not been documented. Further, we suspect that they would have to be large to substantially effect recruitment. This can be illustrated with simple calculations using barnacle life-history data. Previous workers (Possingham and Roughgarden 1990, Alexander and Roughgarden 1996, Dial and Roughgarden 1998, Connolly and Roughgarden 1998, 1999a) have used 5\% per day as an estimate of larval mortality. This estimate is consistent with Balanus balanoides naupliar vs. cyprid numbers in successive plankton hauls (Pyefinch 1949: Table 1). Using this value as a baseline, and assuming that larvae take two weeks to become competent to settle (Brown and Roughgarden 1985), then survivorship from birth to settlement age will be $49 \%\left(0.95^{14}\right)$. If the daily mortality rate doubles, survivorship to settlement age falls to $23 \%\left(0.9^{14}\right)$. This difference (a factor of 2 ) is small relative to the 1-2 orders of magnitude differences in recruitment documented here. Similarly, even a twofold increase in the larval maturation rate (to an average of $1 \mathrm{wk}$ ) would mean that $70 \%$ of larvae become competent to settle (as opposed to 49\%). Again, this difference (a factor of 1.4) is small relative to the recruitment differences documented here. It is unknown whether larvae north of Cape Blanco grow in a more productive environment, on average, than larvae south of it. Moreover, it is not clear whether such differences would lead to differences in larval growth or survival. It seems clear, however, that productivity-induced differences in larval mortality or development rates must be very large to make a substantial contribution to the transitions in recruitment rates documented here.

Finally, recruitment dynamics in central and northern California during El Niño events suggest that large changes in productivity have smaller effects than large changes in offshore transport. Despite dramatically weaker productivity associated with El Niño conditions in the Northeast Pacific (Chelton et al. 1982, Miller et al. 1985, Johnson et al. 1999), decreased recruitment of benthic invertebrates has been observed only when offshore transport rates were normal (Shkedy et al. 1995, Shkedy and Roughgarden 1997). By contrast, increased recruitment has been observed for barnacles and urchins when these events were also associated with anomalously weak offshore transport (Roughgarden et al. 1988, Ebert et al. 1994, Connolly and Roughgarden 1999b).

Evaluating the potential magnitude of the effect of upwelling on recruitment is more complex, due to its spatial component. Nevertheless, we can estimate it with a model that couples barnacle population dynamics to larval transport during upwelling by comparing predicted recruitment rates under oceanographic conditions typical of Oregon and central/northern California. For example, during the first year of the study (the period corresponding to the data shown in Fig. 2), offshore transport rates averaged $124 \mathrm{~m}^{3} / \mathrm{s}$ per $100-\mathrm{m}$ coastline off central and northern California. By contrast, they averaged $12 \mathrm{~m}^{3} / \mathrm{s}$ per $100-\mathrm{m}$ coastline off Oregon. Using life-history parameters for Balanus (Connolly and Roughgarden 1998), assuming that the upwelling front is $32 \mathrm{~km}$ offshore (Roughgarden et al. 1988), and taking the depth of the Ekman layer to be 30 m (Mann and Lazier 1996), this model predicts recruitment rates of $\sim 200$ barnacles per $100 \mathrm{~cm}^{2}$ per month in Oregon and 6 barnacles per $100 \mathrm{~cm}^{2}$ per month in California, a difference of well over an order of magnitude. Note that this calculation accounts only for differences in offshore transport. Upwelling fronts may also be $\geq 80 \mathrm{~km}$ further offshore in California than they are in Oregon (Peterson and Miller 1977, Roughgarden et al. 1988). Models indicate that such differences should further inhibit recruitment in California (Alexander and Roughgarden 1996, Connolly and Roughgarden 1998). In addition, relaxation events are not incorporated in the model used for this calculation; these events bring larvae onshore and thereby promote recruitment (Farrell et al. 1991, Alexander and Roughgarden 1996, Shkedy and Roughgarden 1997). These events are likely to be more frequent in Oregon than in central and northern California. Alongshore winds are weaker and less upwelling favorable in Oregon, and fronts have a comparatively short distance to migrate during relaxation events in order to reach the coast. The fact that relaxation events are not incorporated in the model used above may also explain why the calculated recruitment rates are lower than the observed rates for Balanus (both in California and in 
Oregon). A large proportion of barnacle recruitment, at least in California, occurs during these relaxation events (Farrell et al. 1991, Shkedy and Roughgarden 1997). Whether this is true for mussels as well remains an open question.

This consideration of alternatives is preliminary. Multiple factors may interact in ways that are difficult to predict without appropriate models. For instance, regional differences in rates of larval growth and mortality (if they exist) may amplify or ameliorate the effects of differences in transport processes. A thorough assessment of the relative contributions of these and other potential factors would require field measurements of the effects of each factor on mussel and barnacle lifehistory parameters in California and Oregon. In addition, new models of mussel and barnacle population dynamics would need to be developed that incorporate more biological and physical detail than is present in existing models (e.g., Alexander and Roughgarden 1996, Connolly and Roughgarden 1999a). For instance, to fully capture the compounding of differences in larval mortality rates through time, a time lag between larval production and competency for settlement would be required. Once such models have been developed and calibrated, the effects on recruitment rates of observed regional differences in these factors could be evaluated with sensitivity analyses. Such an endeavor is beyond the scope of this paper. However, the preliminary assessment offered above does support the claim that regional differences in transport processes are a major cause of the transition in recruitment rates.

\section{Conclusions}

A very large transition in recruitment rates occurred near Cape Blanco in 1996 and 1997: recruitment was significantly and markedly higher north of this headland, where upwelling is weak, than south of it, where upwelling is strong. This is consistent with the hypothesis that regional differences in upwelling intensity are a major cause of corresponding differences in benthic community structure (Connolly and Roughgarden 1998). This transition in recruitment was larger, more abrupt, and more consistent across taxa than a coincident shift in percentage-cover of adult sessile invertebrates, which was significant only for competitive dominants (Connolly and Roughgarden 1998). These differences between recruitment and percentage-cover transitions are consistent with models predicting more intense competition where transport processes facilitate recruitment (Menge and Sutherland 1987, Connolly and Roughgarden 1998, 1999a). Within central and northern California, recruitment neither increased nor decreased significantly with latitude. Instead, we propose that recruitment decreased both north and south from a region extending roughly from San Francisco to Monterey Bay. Larvae may be retained more nearshore within this region than north or south of it.

More broadly, these results, together with previous work on regional patterns in community structure (Connolly and Roughgarden 1998, 1999a), suggest that larval transport processes interact with benthic community processes at regional scales, and that the effects of these interactions can be very large. Small-scale experimental studies have played a crucial role in marine ecology, so resolving controversies about the generality of inferences made from these studies is important. Such controversies are fueled, at least in part, by regional differences in the results of experimental manipulations (Underwood and Denley 1984, Foster 1990, 1991, Paine 1991). A promising approach to resolving these differences involves making the regional context of local ecological processes an integral part of our conception of benthic communities (cf. Roughgarden et al. 1988, Connolly and Roughgarden 1999a, Hughes et al. 1999). The ecological significance of this study's findings underscores the essential role of regional-scale monitoring in this process.

\section{ACKNOWLEDGMENTS}

We are particularly grateful to B. Daley and G. Hudson for help in the field. Additional field assistance was ably provided by I. C. Kaplan, R. A. Muench, N. Boyce, T. Angel, A. Cameron, B. Chipman, J. Ehlig, S. Etchemendy, J. Furler, M. Foley, T. Mulch, J. Nichols, L. Ryan, M. Webster, S. White, J. Whitsett, M. Willis, M. Dutton, and A. Way. R. B. Emlet, T. M. Farrell, and J. S. Pearse generously shared the results of unpublished research. For advice, assistance, criticism, and support during manuscript preparation, we thank G. Allison, E. Berlow, J. Burnaford, T. Freidenburg, B. Grantham, P. Halpin, J. Lubchenco, S. Navarrete, K. Nielsen, C. Reimer, E. Sanford, C. Trowbridge, T. Freidenburg, E. Bjorkstedt, C. Knight, P. Vitousek, D. Gordon, J. Koseff, J. Huisman, R. Dugdale, J. Witman, and three anonymous reviewers. We are grateful to the Pacific Fisheries Environmental Laboratory (National Marine Fisheries Service) for making upwelling indices available. We thank the Monterey Bay National Marine Sanctuary (permit MBNMS-07-97), the California Department of Fish and Game (permits 803003-01 and 80307202), and the California Department of Parks and Recreation for permission to conduct this research. We gratefully acknowledge financial support from the following sources: the American Museum of Natural History Lerner Gray Fund for Marine Research, the Northern California Phi Beta Kappa Association, the Andrew W. Mellon Foundation, the David and Lucile Packard Foundation, the Wayne and Gladys Valley Foundation, Robert Lundeen, a John Simon Guggenheim Fellowship, and the National Science Foundation. This is contribution number 24 of the Partnership for Interdisciplinary Studies of Coastal Oceans (PISCO): A Long-Term Ecological Consortium funded by the David and Lucile Packard Foundation.

\section{Literature Cited}

Alexander, S. E., and J. Roughgarden. 1996. Larval transport and population dynamics of intertidal barnacles: a coupled benthic/oceanic model. Ecological Monographs 66:259275.

Bakun, A., and R. H. Parrish. 1982. Turbulence, transport, and pelagic fish in the California and Peru current systems. California Cooperative Fisheries Investigations Reports 23: 99-112.

Barry, J. P., and M. J. Tegner. 1989. Inferring demographic processes from size-frequency distributions: simple models indicate specific patterns of growth and mortality. Fishery Bulletin 88:13-19. 
Berlow, E. L. 1997. From canalization to contigency: historical effects in a successional rocky intertidal community. Ecological Monographs 67:435-460.

Bjorkstedt, E. P. 1998. Remote sensing and ichthyoplankton ecology of coastal upwelling fronts of central California. Dissertation. Stanford University, Stanford, California, USA.

Booth, D. J., and D. M. Brosnan. 1995. The role of recruitment dynamics in rocky shore and coral reef communities. Advances in Ecological Research 26:309-385.

Brink, K. H. 1983. The near-surface dynamics of coastal upwelling. Progress in Oceanography 12:223-257.

Brown, S. K., and J. Roughgarden. 1985. Growth, morphology, and laboratory culture of larvae of Balanus glandula (Cirripedia: Thoracica). Journal of Crustacean Biology 5:574-590.

Caley, M. J., M. H. Carr, M. A. Hixon, T. P. Hughes, G. P. Jones, and B. A. Menge. 1996. Recruitment and the local dynamics of open marine populations. Annual Review of Ecology and Systematics 27:477-500.

Chelton, D. B., P. A. Bernal, and J. A. McGowan. 1982. Large-scale interannual physical and biological interaction in the California Current. Journal of Marine Research 40: 1095-1125.

Connell, J. 1985. The consequences of variation in initial settlement vs. post-settlement mortality in rocky intertidal communities. Journal of Experimental Marine Biology and Ecology 93:11-45.

Connolly, S. R., and J. Roughgarden. 1998. A latitudinal gradient in intertidal communtiy structure: evidence for an oceanographically based synthesis of marine community theory. American Naturalist 151:311-326.

Connolly, S. R., and J. Roughgarden. 1999a. Theory of marine communities: competition, predation, and recruitmentdependent interaction strength. Ecological Monographs 69: 277-296.

Connolly, S. R., and J. Roughgarden. 1999b. Increased recruitment of northeast Pacific barnacles during the $1997 \mathrm{El}$ Niño. Limnology and Oceanography 44:466-469.

Daniel, W. W. 1990. Applied nonparametric statistics. Second edition. PWS-Kent, Boston, Massachusetts, USA.

Dayton, P. K. 1971. Competition, disturbance, and community organization: the provision and subsequent utilization of space in a rocky intertidal community. Ecological Monographs 41:351-389.

Dial, R. J., and J. Roughgarden. 1998. Theory of marine communities: the intermediate disturbance hypothesis. Ecology 79:1412-1424.

Dungan, M. L. 1985. Competition and the morphology, ecology, and evolution of acorn barnacles: an experimental test. Paleobiology 11:165-173.

Ebert, T. A. 1983. Recruitment in echinoderms. Pages 169203 in M. Jangoux and J. Lawrence, editors. Echinoderm studies. A. A. Balkema, Salem, New Hampshire, USA.

Ebert, T. A., and M. P. Russell. 1988. Latitudinal variation in size structure of the west coast purple sea urchin: a correlation with headlands. Limnology and Oceanography 33:286-294.

Ebert, T. A., S. C. Schroeter, J. D. Dixon, and P. Kalvass. 1994. Settlement patterns of red and purple sea urchins (Strongylocentrotus franciscanus and S. purpuratus) in California, USA. Marine Ecology Progress Series 111:41-52.

Ekman, V. W. 1905. On the influence of the earth's rotation on ocean currents. Arkiv för Matematik, Astronomi och Fysik 2:52.

Farrell, T., D. M. Bracher, and J. Roughgarden. 1991. Crossshelf transport causes recruitment to intertidal populations in central California. Limnology and Oceanography 36: 279-288

Foster, M. S. 1990. Organization of macroalgal assemblages in the Northeast Pacific: the assumption of homogeneity and the illusion of generality. Hydrobiologia 192:21-33.

Foster, M. S. 1991. Rammed by the Exxon Valdez, a reply to Paine. Oikos 62:93-96.

Foster, M. S., A. P. DeVogelaere, C. Harrold, J. S. Pearse, and A. B. Thum. 1988. Causes of spatial and temporal patterns in rocky intertidal communities of central and northern California. Memoirs of the California Academy of Sciences, number 9. California Academy of Sciences, San Francisco, California, USA

Gaines, S. D., and M. D. Bertness. 1992. Dispersal of juveniles and variable recruitment in sessile marine species. Nature 360:579-580.

Gaines, S. D., and J. Roughgarden. 1985. Larval settlement rate: a leading determinant of structure in an ecological community of the marine intertidal zone. Proceedings of the National Academy of Sciences (USA) 82:3707-3711.

Gaines, S. D., and J. Roughgarden. 1987. Fish in offshore kelp forests affect recruitment to intertidal barnacle populations. Science 235:479-481.

Graham, W. M., J. G. Field, and D. C. Potts. 1992. Persistent "upwelling shadows" and their influence on zooplankton distributions. Marine Biology 114:561-570.

Grantham, B. A. 1997. Coastal upwelling, larval recruitment, and the dynamics of upper intertidal barnacle communities. Dissertation. Stanford University, Stanford, California, USA.

Hines, A. H. 1976. Comparative reproductive ecology of three species of intertidal barnacles. Dissertation. University of California, Berkeley, California, USA.

Hughes, T. P., A. H. Baird, E. A. Dinsdale, V. J. Harriott, N. A. Moltschaniwskyj, M. S. Pratchett, J. E. Tanner, and B. L. Willis. In press. Latitudinal patterns in larval recruitment: detecting regional variation using meta-analysis and large-scale sampling. Ecology.

Hughes, T. P., A. H. Baird, E. A. Dinsdale, N. A. Moltschaniwskyj, M. S. Pratchett, J. E. Tanner, and B. L. Willis. 1999. Patterns of recruitment and abundance of corals along the Great Barier Reef. Nature 397:59-63.

Johnson, K. S., F. P. Chavez, and G. E. Friederich. 1999. Continental-shelf sediment as a primary source of iron for coastal phytoplankton. Nature 398:697-700.

Liu, W. T., W. Tang, and H. Hu. 1998. Spaceborne sensors observe El Niño's effects on ocean and atmosphere in north Pacific. Eos 79:249.

Manly, B. F. J. 1997. Randomization, bootstrap and Monte Carlo methods in biology. Second edition. Chapman \& Hall, London, UK.

Mann, K. H., and J. R. N. Lazier. 1996. Dynamics of marine ecosystems. Second edition. Blackwell Science, Cambridge, Massachusetts, USA.

Meese, R. J. 1993. Effects of predation by birds on gooseneck barnacle Pollicipes polymerus Sowerby distribution and abundance. Journal of Experimental Marine Biology and Ecology 166:47-64.

Menge, B. A. 1991. Relative importance of recruitment and other causes of variation in rocky intertidal community structure. Journal of Experimental Marine Biology and Ecology 146:69-100.

Menge, B. A. 1992. Community regulation: Under what conditions are bottom-up factors important on rocky shores? Ecology 73:755-765.

Menge, B. A. 2000. Recruitment vs. post-recruitment processes as determinants of barnacle population abundance on Oregon rocky shores. Ecological Monographs 70:265288.

Menge, B. A., E. L. Berlow, C. A. Blanchette, S. A. Navarrete, and S. B. Yamada. 1994. The keystone species concept: variation in interaction strength in a rocky intertidal habitat. Ecological Monographs 64:249-286. 
Menge, B. A., B. A. Daley, P. A. Wheeler, E. Dahlhoff, E. Sanford, and P. T. Strub. 1997. Benthic-pelagic links and rocky intertidal communities: Bottom-up effects on topdown control? Proceedings of the National Academy of Sciences (USA) 94:14530-14535.

Menge, B. A., and J. P. Sutherland. 1987. Community regulation: variation in disturbance, competition, and predation in relation to environmental stress and recruitment. American Naturalist 130:730-757.

Miller, B. A., and R. B. Emlet. 1997. Influence of nearshore hydrodynamics on larval abundance and settlement of sea urchins Stronglocentrotus franciscanus and $S$. purpuratus in the Oregon upwelling zone. Marine Ecology Progress Series 148:83-94.

Miller, C. B., H. P. Batchelder, R. D. Brodeur, and S. Johnson. 1985. Response of the zooplankton and ichthyoplankton off Oregon to the El Niño event of 1983. Pages 185-187 in W. S. Wooster and D. L. Fluharty, editors. El Niño North: Niño effects in the Eastern Subarctic Pacific Ocean. Washington Sea Grant Program, Seattle, Washington, USA.

Miller, K. M. 1992. The biology of barnacles. Dissertation. Stanford University, Stanford, California, USA.

Navarrete, S. A. 1996. Variable predation: effects of whelks on a mid-intertidal successional community. Ecological Monographs 66:301-321.

Navarrete, S. A., and B. A. Menge. 1996. Keystone predation and interaction strength: interactive effects of predators on their main prey. Ecological Monographs 66:409-429.

Paine, R. T. 1974. Intertidal community structure. Experimental studies on the relationship between a dominant competitor and its principal predator. Oecologia 15:93-120.

Paine, R. T. 1981. Barnacle ecology: Is competition important? The forgotten roles of disturbance and predation. $\mathrm{Pa}-$ leobiology 7:553-560.

Paine, R. T. 1991. Between Scylla and Charybdis: Do some kinds of criticism merit a response? Oikos 62:90-92.

Palma, A. T., R. S. Steneck, and C. J. Wilson. 1999. Settlement-driven, multiscale demographic patterns of large benthic decapods in the Gulf of Maine. Journal of Experimental Marine Biology and Ecology 241:107-136.

Parker, H. A. 1996. Variations in coastal circulation off central California, spring-summer 1993, 1994, 1995. Thesis. Naval Postgraduate School, Monterey, California, USA.

Parrish, R. H., C. S. Nelson, and A. Bakun. 1981. Transport mechanisms and reproductive success of fishes in the California Current. Biological Oceanography 1:175-203.

Peterson, W. T., and C. B. Miller. 1977. Seasonal cycle of zooplankton abundance and species composition along the central Oregon coast. Fishery Bulletin 75:717-724.

Possingham, H. P., and J. Roughgarden. 1990. Spatial population dynamics of a marine organism with a complex life cycle. Ecology 71:973-985.

Pyefinch, K. A. 1949. Short-period fluctuations in the numbers of barnacle larvae, with notes on comparisons between pump and net plankton hauls. Journal of the Marine Biological Association of the United Kingdom 28:353-369.

Robles, C. D. 1997. Changing recruitment in constant species assemblages: implications for predation theory in intertidal communities. Ecology 78:1400-1414.

Rosenfeld, L. K., F. B. Schwing, N. Garfield, and D. E. Tracy. 1997. Bifurcated flow from an upwelling center: a cold water source for Monterey Bay. Continental Shelf Research 14:931-964.

Roughgarden, J. 1986. A comparison of food-limited and space-limited animal competition communities. Pages $492-$ 516 in J. Diamond and T. Case, editors. Community ecology. Harper \& Row, New York, New York, USA.

Roughgarden, J., S. D. Gaines, and H. P. Possingham. 1988. Recruitment dynamics in complex life cycles. Science 241: 1460-1466.
Roughgarden, J., Y. Iwasa, and C. Baxter. 1985. Demographic theory for an open marine population with space-limited recruitment. Ecology 66:54-67.

Roughgarden, J., J. T. Pennington, D. Stoner, S. Alexander, and K. Miller. 1991. Collisions of upwelling fronts with the intertidal zone: the cause of recruitment pulses in barnacle populations of central California. Acta Enpcologica 12:35-51.

Roughgarden, J., Y. Shkedy, B. A. Grantham, and E. P. Bjorkstedt. 1996. Barnacle larvae in relation to mesoscale features in the California Current off central California. Eos Transactions Supplement 76:OS157.

Sanford, E. 1999. Oceanographic influences on rocky intertidal communities: coastal upwelling, invertebrate growth rates, and keystone predation. Dissertation. Oregon State University, Corvallis, Oregon, USA.

Schwing, F. B., D. M. Husby, N. Garfield, and D. E. Tracy. 1991. Mesoscale oceanic response to wind events off central California in spring 1989: CTD surveys and AVHRR imagery. California Cooperative Fisheries Investigations Reports 32:47-62.

Shkedy, Y., D. Fernandez, C. Teague, J. Vesecky, and J. Roughgarden. 1995. Detecting upwelling along the central coast of California during an El Niño year using HF-radar. Continental Shelf Research 15:803-814.

Shkedy, Y., and J. Roughgarden. 1997. Barnacle recruitment and population dynamics predicted from coastal upwelling. Oikos 80:487-498.

Sokal, R. R., and F. J. Rohlf. 1995. Biometry. Third edition. W. H. Freeman \& Company, New York, New York, USA.

Strathmann, M. F. 1987. Reproduction and development of marine invertebrates of the northern Pacific coast. University of Washington Press, Seattle, Washington, USA.

Underwood, A. J. 1981. Structure of a rocky intertidal community in New South Wales: patterns of vertical distribution and seasonal change. Journal of Experimental Marine Biology and Ecology 51:57-85.

Underwood, A. J., and M. G. Chapman. 1996. Scales of spatial patterns of distribution of intertidal invertebrates. Oecologia 107:212-224.

Underwood, A. J., and E. Denley. 1984. Paradigms, explanations, and generalizations in models for the structure of intertidal communities on rocky shores. Pages 151-180 in D. R. Strong, D. Simberloff, L. G. Abele, and A. B. Thistle, editors. Ecological communities: conceptual issues and the evidence. Princeton University Press, Princeton, New Jersey, USA

Underwood, A. J., E. J. Denley, and M. J. Moran. 1983. Experimental analyses of the structure and dynamics of mid-shore rocky intertidal communities in New South Wales. Oecologia 56:202-219.

U.S. GLOBEC. 1994. Eastern Boundary Current Program: a science plan for the California Current. U.S. global ocean ecosystems dynamics, report number 11 . U.S. GLOBEC Scientific Steering Coordinating Office, Berkeley, California, USA.

Wing, S. R., L. W. Botsford, J. L. Largier, and L. E. Morgan. 1995. Spatial structure of relaxation events and crab settlement in the northern California upwelling system. Marine Ecology Progress Series 128:199-211.

Wing, S. R., L. W. Botsford, S. V. Ralston, and J. L. Largier. 1998. Meroplanktonic distribution and circulation in a coastal retention zone of the northern California upwelling system. Limnology and Oceanography 43:1710-1721.

Wootton, J. T. 1993. Size-dependent competition: effects on the dynamics vs. the end point of mussel bed succesion. Ecology 74:195-206.

Wootton, J. T. 1994. Predicting direct and indirect effects: an integrated approach using experiments and path analysis. Ecology 75:151-165. 